\title{
Quando os índios escolhem os seus aliados: as relações de "amizade" entre os minuanos e os lusitanos no sul da América portuguesa (c.1750-1800)
}

\section{When the Indians choose their allies: \\ the "friendship" relations between the Minuanos and the Lusitanian in the south of Portuguese America (c.1750-1800)}

ELISA FRÜHAUF GARCIA

Doutora em História pela Universidade Federal Fluminense Pós-doutoranda em Antropologia na Universidade Estadual de Campinas Bolsista CNPq elisafg@terra.com.br

RESUMO Durante a sua expansão em direção ao sul da América, os portugueses selaram várias alianças com os índios minuanos, através das quais conseguiram viabilizar o seu estabelecimento na região, cujo domínio estava em constante disputa com os espanhóis. Tais alianças, porém, se inseriam dentro das necessidades dos próprios índios, que nelas buscavam contemplar os seus interesses específicos. Perceber em que bases as relações entre ambos foram construídas e alimentadas por parte dos minuanos e como eles buscavam, por meio das mesmas, atingir os seus interesses é o propósito deste artigo.

Palavras-chave índios minuanos, expansão portuguesa, políticas indígenas.

Artigo recebido em: setembro/2008. 
ABSTRACT During the Portuguese expansion to South America, they sealed many alliances with the Minuanos Indians, through which the Portuguese could make possible their settlement in the region, whose possession was under continual dispute with the Spaniards. Such alliances, though, were also necessary for the Indians themselves, who intended to satisfy their own interests through them. This article aims to perceive in which bases the relationships between the Lusitanian and the Minuanos were built, and how these bases were sustained and used by the latter to achieve determined objectives.

Keywords Minuanos Indians, Portuguese expansion, indigenous policies.

Desde o princípio da expansão dos portugueses em direção ao sul da América, os índios minuanos desenvolveram com eles relações de aliança, as quais possibilitaram o trânsito dos lusitanos pela região e os auxiliaram em vários momentos, tanto na manutenção da Colônia de Sacramento quanto no seu estabelecimento e permanência no atual estado do Rio Grande do Sul. Devido a tais alianças, os minuanos foram considerados pela historiografia como os principais aliados dos portugueses. Em sua grande maioria, os autores partiam do pressuposto de que os minuanos eram aliados absolutos dos lusitanos e, consequentemente, que os interesses deste grupo indígena eram unívocos e estavam diretamente vinculados aos interesses dos portugueses. Por outro lado, as mesmas abordagens não consideravam eventuais laços estabelecidos entre os minuanos e os castelhanos ou com os índios missioneiros ${ }^{1}$, sendo os últimos sempre caracterizados como aliados incondicionais dos espanhóis. ${ }^{2}$

Desenvolvia-se, portanto, um enfoque dicotômico e sem maiores problematizações, onde as alianças na região entre os europeus e os índios teriam se estabelecido nos primórdios da ocupação do espaço e não estariam sujeitas a modificações e a reformulações ao longo do tempo, iniciando-se com a expansão portuguesa e perdurando até o princípio

1 Termo utilizado para designar os índios, em sua maioria guaranis, estabelecidos nos trinta povos jesuíticos do Paraguai.

2 Sobre a aliança dos minuanos com os portugueses e a sua inimizade com os missioneiros veja-se: Boxer, Charles. A idade de ouro do Brasil: dores de crescimento de uma sociedade colonial. Rio de J aneiro: Nova Fronteira, 2000, p.258. Quanto à preferência dos minuanos pelos portugueses veja-se: Aurélio Porto, "O minuano na toponímia riograndense", Revista do Instituto Histórico e Geográfico do Rio Grande do Sul. Porto Alegre: 0 Instituto, 20 trimestre de 1938, p.103; Rodrigues, J osé Honório. O Continente do Rio Grande. Rio de J aneiro: Edições São J osé, 1954, p.33; Barrios Pintos, Anibal. Aborigenes e indigenas del Uruguay. Montevidéu: Ediciones de la Banda Oriental, 1975, p.37; Acosta y Lara, Eduardo F. La guerra de los charrúas. Montevidéu: Talleres de Loreto Editores, 1998, p.26; Cesar, Guilhermino. História do Rio Grande do Sul. Porto Alegre: Globo, 1980, p.25. 
do século XIX. Trabalhos recentes, mais preocupados com as dinâmicas dos índios, apontaram para a pouca pertinência deste tipo de abordagem esquemática, ${ }^{3}$ pois as relações dos diferentes grupos indígenas entre si e deles com os ibéricos eram mutáveis e dependiam de uma série de variáveis e matizes, tais como as prioridades dos próprios índios, as diferentes conjunturas ibéricas e os objetivos dos agentes locais, os quais nem sempre se coadunavam com as diretrizes metropolitanas.

Assim, este artigo pretende analisar as alianças dos minuanos com os portugueses enfocando o seu caráter relacional e contextual, procurando evidenciar e compreender quais eram as vantagens obtidas pelos índios e por quais meios os próprios se construíram, em certas situações, como aliados dos lusitanos. Paralelamente, também busca contemplar, quando possível, as diferentes interpretações dos minuanos sobre o contexto histórico no qual estavam inseridos e como eles, a partir destas interpretações, selecionaram na trajetória dos seus relacionamentos com os europeus e com os demais grupos indígenas da região os aspectos que lhes eram mais favoráveis para se vincularem aos portugueses, com o claro propósito de obterem determinados benefícios em momentos específicos.

Da perspectiva dos estados europeus, a obtenção de alianças com os índios era uma parte fundamental da sua política expansionista. Tais alianças eram ainda mais importantes nas regiões fronteiriças, onde os estados competiam entre si por territórios e vassalos. Por outro lado, nas disputas territoriais entre os estados europeus na América portuguesa, quando de "invasões estrangeiras", como no caso dos holandeses no nordeste e dos franceses no Rio de J aneiro, uma das características destas disputas foram as alianças estabelecidas entre os grupos indígenas e os representantes dos diferentes estados em conflito, quando aqueles combatiam ao lado de um ou de outro, e também "mudavam" de lado, e obtinham, dessa forma, destaque e vantagens junto aos seus respectivos coligados. Independente, porém, dos diversos contextos de disputas territoriais nas quais os índios eram aliados importantes ou, em muitos casos, essenciais, esta situação pressupunha para os estados europeus uma necessidade constante de atrair as populações nativas. Tal atração era desenvolvida, usualmente, a partir da concessão de presentes e/ou do oferecimento de vantagens maiores nas suas alianças, ${ }^{4} \mathrm{e}$, através de tais "atrativos", concorriam pela

3 Para uma relativização da suposta inimizade dos minuanos com os membros da sociedade colonial espanhola veja-se: Bracco, Diego. Charruas, guenoas y guaraníes. Interacción y destrucción: indígenas en el Río de la Plata. Montevidéu: Linardi y Risso, 2004, p.329; Wilde, Guillermo. “Guaraníes, 'gauchos', e 'indios infieles' en el proceso de disgregación de las antiguas doctrinas jesuíticas del Paraguay", Suplemento Antropologico. Asunción: Universidad Católica, diciembre de 2003, vol.XXXVIII, n.2.

4 Para a disputa dos estados europeus pela aliança com os índios na região da Amazônia, por exemplo, veja-se: Domingues, Ângela. Quando os índios eram vassalos: colonização e relações de poder no Norte do Brasil na segunda metade do século XVIII. Lisboa: Comissão Nacional para as Comemorações dos Descobrimentos Portugueses, 2000, p.232 e Farage, Nádia. As muralhas dos sertões: os povos indígenas no Rio Branco e a colonização. Rio de J aneiro: Paz e Terra; ANPOCS, 1991. 
primazia nos acordos com os índios. Por conseguinte, a necessidade de estabelecer alianças com os grupos nativos era uma questão colocada nos debates sobre questões territoriais nas cortes e, com o passar do tempo, a presença daqueles nas regiões de fronteira começou a ser considerada como uma importante variável nas políticas expansionistas dos Impérios ibéricos. ${ }^{5}$ Para o caso específico dos portugueses, segundo Russell-Wood, eles sempre buscavam formas de convivência com os grupos nativos, visando, principalmente, mantê-los distantes de alianças com os seus inimigos europeus. ${ }^{6}$ Assim, conclui o autor, os lusitanos construíram o seu Império "com e não isoladamente contra os povos com os quais entraram em contato". 7

A percepção das populações indígenas como um elemento importante na conquista e manutenção das possessões americanas da Coroa portuguesa é uma questão já posta há algum tempo pela historiografia brasileira, ${ }^{8}$ embora nem sempre devidamente considerada em trabalhos sobre a expansão lusitana e o seu estabelecimento e manutenção na América. De fato, as relações dos europeus com os índios visando que estes funcionassem como defesa tanto contra as ameaças internas, principalmente grupos indígenas hostis à colonização, quanto contra as externas, outros estados europeus, foram uma constante ao longo da colonização. ${ }^{9}$ Se tais alianças foram uma constante, os mecanismos através dos quais foram seladas e a sua durabilidade passaram por vários momentos, pois elas dependiam não apenas dos interesses dos europeus, mas também das próprias populações nativas, as quais ora viam vantagens em tais acordos, ora preferiam outros caminhos.

\section{A construção histórica das alianças entre os portugueses e os minuanos}

Antes mesmo de ocuparem o atual território do Rio Grande do Sul, os luso-brasileiros estabelecidos em Laguna, situada no sul do atual estado de Santa Catarina, desenvolveram uma política de atração dos minuanos, baseada na outorga de presentes e de símbolos de prestígio e distinção.

5 Alexandre, Valentim. Os sentidos do Império. Questão nacional e questão colonial na Crise do Antigo Regime Português. Porto: Edições Afrontamento, 1993, p.97.

6 Russell-Wood, A.J.R. Um mundo em movimento: os portugueses na África, Ásia e América, (1415-1808). Lisboa: DIFEL, 1998. p.34.

7 Russell-Wood, A.J.R. Um mundo em movimento: os portugueses na África, Ásia e América, (1415-1808). p.16, grifos do autor.

8 Prado J únior, Caio. Formação do Brasil contemporâneo. São Paulo: Brasiliense, s/d. [1942]. p.91. Sobre o tema veja-se também: Puntoni, Pedro. A Guerra dos Bárbaros: Povos Indígenas e a Colonização do Sertão Nordeste do Brasil, 1650-1720. São Paulo: Hucitec; Editora da Universidade de São Paulo; FAPESP, 2002. p.49.

9 Schwart, Stuart \& Salomon, Frank. "New Peoples and New Kinds of People: Adaptation, Readjustment, and Ethnogenesis in South American Indigenous Societies". In:___ (eds.) The Cambridge History of the Native Peoples of the Americas. Volume III: South America, part 2. Cambridge New York: Cambridge University Press, 1999. 
Através de dados recolhidos por informantes castelhanos, os portugueses proviam os minuanos de produtos por eles apreciados, principalmente aguardente e erva-mate. Em certa ocasião, algumas lideranças também foram presenteadas com bengalas adornadas por um castão de prata, elaboradas especialmente com o fim de atrair a sua "amizade". ${ }^{10}$

Apesar de um esforço contínuo por parte dos portugueses, a aliança com os minuanos não era absoluta, mas variava de acordo com vários quesitos e necessitava de uma constante realimentação. Sabendo disto, os lusitanos conviviam com o temor de uma virada dos interesses dos índios para o lado dos espanhóis, o que comprometeria os seus projetos expansionistas. Assim, após a entrega de alguns presentes, comentou-se que:

0 mimo que por eles mandei ao maioral dos minuanos me noticia entregaram: 0 qual ficou muito satisfeito, mostrando grande amizade que com os portugueses deseja ter, e se puseram logo na parag em vizinhos do Rio Grande que se chama o morro de São Miguel, esperando a ordem que lhes hei de mandar: mas nunca farei fundamento em palavras, nem amizades do gentio do cabelo corredio pela experiência que tenho deles, porque os acho indômitos na sua palavra, e estes castelhanos [informantes] me noticiam que tanto que se lhes falta com os mimos em toda a ocasião se tomam rebeldes, que virá a custar mais os gastos que 0 interesse que ele poderá dar. ${ }^{11}$

As alianças com os minuanos eram especialmente necessárias para a manutenção da Colônia de Sacramento, alvo de freqüentes investidas dos castelhanos. A dependência dos lusitanos do auxílio dos índios fica patente em uma carta de 17 de outubro de 1715, na qual dom J oão, rei de Portugal, admoestava o novo governador da Colônia, Manoel Gomes Barbosa, a conservar:

(...) grande cautela com os índios vizinhos, mas com esta advertência que os não escandalizeis, antes procurareis atraí-los com indústria, tendo entendido que a sua amizade vos pode senvir de grande benefício, e pelo contrário a sua inimizade de notável prejuízo; e que poderão os castelhanos com a mão destes bárbaros fazer-nos dano, e impedir-vos o uso da campanha, sem a qual não poderá subsistir a Colônia. ${ }^{12}$

Os minuanos, por sua vez, sabiam transformar as disputas entre portugueses e espanhóis em uma oportunidade para a satisfação dos seus objetivos. Assim, na mesma época em que o governador de Sacramento foi admoestado a empregar todo o empenho na manutenção das pazes com

10 Correspondência do Capitão-mor da Laguna, Francisco de Brito Peixoto. In: Documentos interessantes para a história e costumes de São Paulo. São Paulo: Arquivo do Estado de São Paulo, 1901. vol.32, anexo K, p.288.

11 Correspondência do Capitão-mor da Laguna, Francisco de Brito Peixoto. In: Documentos interessantes para a história e costumes de São Paulo. p.290. Grifos meus.

12 Arquivo Nacional/Rio de J aneiro - Fundo: Vice-reinado, cx.746, pct.02. Grifos meus. 
os minuanos, três caciques o procuraram com a intenção de tornarem-se cristãos, porém sob uma condição: que fosse trazida do Rio de J aneiro uma sua irmã e sobrinha, a qual, não se sabe ao certo em quais circunstâncias, fora levada àquela cidade. ${ }^{13} \mathrm{~A}$ solicitação dos caciques obteve parecer favorável do Conselho Ultramarino. Os seus membros consideraram que só assim seriam obtidos os benefícios das pazes com os minuanos, tidos então como os mais valorosos da campanha. ${ }^{14} \mathrm{~A}$ sua irmã deveria ser localizada no Rio de J aneiro e, caso estivesse na condição de escrava, seria comprada à custa da fazenda real e, posteriormente, enviada ao sul. ${ }^{15}$

Após a fundação do primeiro estabelecimento oficial português no atual estado do Rio Grande do Sul, o forte J esus-Maria-J osé16, em 1737, os lusitanos passaram a ansiar ainda mais o estreitamento das relações com os minuanos, considerando a possibilidade de utilizá-los como base populacional para o novo núcleo colonial. Assim, o primeiro governador do presídio, André Ribeiro Coutinho, descreveu em suas memórias o esforço despendido em tentativas de aproximação com aqueles índios: "Os tratei e fiz presentes, pela Fazenda Real, proporcionando aos seus usos e em nome de S.M. dei a um a nomeação e o bastão de capitão". ${ }^{17}$ Entrementes, as tentativas de aproximação e atração dos minuanos para o povoado de Rio Grande prosseguiram, com resultados diversos. No final da década de 1740 , os lusitanos conseguiram atrair um grupo de minuanos para o forte. Segundo o governador Diogo Osório Cardoso:

Sendo Deus Nosso Senhor servido abrir os olhos ao gentio minuano para virem a este Rio Grande a pedir o batismo, que há tantos anos se pretende [...] procurei com todo o desvelo os caminhos para a sua execução, ordenando ao tenente de dragões Pedro Pereira Chaves, comandante da Guarda do Chuí, na vizinhança do gentio, o tratasse com toda a brandura e despendesse com eles algumas miçangas para quando chegassem os missionários estar dispostos a aceitar e receber a fé [...] e por não ser justo que se perca uma ocasião tão ditosa, ordeno ao Comissário de Mostras que, sem embargo da dúvida que põe a esta despesa, vá com o tesoureiro da Fazenda Real comprar roupas aonde as houver capazes e mais fardas para vestir até sessenta índios pequenos de ambos os sexos que pretendo se batizem a 15 de agosto. ${ }^{18}$

13 Almeida, Maria Regina Celestino de. Metamorfoses indígenas: identidade e cultura nas aldeias coloniais do Rio de J aneiro. Rio de J aneiro: Arquivo Nacional, 2003. p.99.

14 Termo empregado para designar a região não ocupada efetivamente pelos Impérios ibéricos, embora de constante trânsito e atividades econômicas por parte de súditos de ambas as Coroas e de intenso relacionamento dos mesmos com os grupos indígenas.

15 Almeida, Maria Regina Celestino de. Metamorfoses indígenas: identidade e cultura nas aldeias coloniais do Rio de J aneiro. p.99.

16 Deste forte originou-se a freguesia de Rio Grande, elevada a vila algum tempo depois.

17 Memória dos serviços prestados pelo mestre-de-campo André Ribeiro Coutinho no governo do Rio Grande de São Pedro. In: Revista do Instituto Histórico e Geográfico do Rio Grande do Sul. Porto Alegre: 0 Instituto, 4ํ․ trimestre de 1936. 16:245.

18 Registro de uma ordem que deu o Coronel Governador Diogo Osório Cardoso para serem enroupados os índios minuanos. Rio de São Pedro, 7 de agosto de 1749. In: Anais do Arquivo Histórico do Rio Grande do Sul. Porto Alegre: Instituto Estadual do Livro, 1977. vol.1, pp.235-236. 
Por que, após tantos anos de tentativas de atração dos minuanos, justamente neste momento este grupo aceitou as propostas? Para muitos autores, os portugueses e os espanhóis se aproveitaram, e também potencializaram, das rivalidades existentes entre a população indígena da região, tirando vantagens destas. No entanto, o mesmo pode ser dito em relação aos índios, pois eles percebiam na presença dos portugueses uma oportunidade de obter aliados e/ou proteção contra os seus contrários. A se dar crédito a uma memória anônima, este grupo teria procurado os lusitanos solicitando o batismo porque estavam sendo pressionados por outros grupos indígenas e perceberam nos portugueses uma possibilidade de sobrevivência. Segundo a memória: "com serem os mais valorosos da campanha, eram já em pequeno número, porque os Índios, chamados Tapes, e outros chamados Charruas, em muito maior número, os andavam acabando e destruindo". ${ }^{19}$ Sentindo-se pressionados, segundo 0 autor da memória não pelos europeus, mas pelos demais grupos indígenas da região, aqueles minuanos procuraram auxílio na freguesia de Rio Grande.

É importante ressaltar que os portugueses foram usados pelo grupo minuano como aliados contra outros indígenas. Situação semelhante foi a dos índios do gato ou temininó, localizados na baía de Guanabara no século XVI. Ao se encontrarem em uma conjuntura adversa, pressionados pelos seus contrários e sem maiores alternativas, aproveitaram a presença dos portugueses para selarem uma aliança e se fortalecerem. A partir de então, tornaram-se os principais aliados dos lusitanos e costumavam empregar esta situação do seu passado para embasar os seus pleitos junto da sociedade colonial. ${ }^{20}$

A despeito de um grupo composto por aproximadamente sessenta minuanos ter permanecido na vila, as negociações sobre o seu aldeamento foram controversas. 0 governador planejava aldeá-los e, com tal fim, já havia selado um acordo com um dos caciques, chamado dom Xiclano. Descrito como um "índio amável, pela sua gentileza, gênio doce e boas maneiras", dom Xiclano inicialmente ajustou a transferência dos seus liderados para Rio Grande, onde seriam aldeados. Os moradores da vila, no entanto, não aceitaram o aldeamento, alegando que os seus rebanhos seriam roubados pelos índios e as suas terras apropriadas pelos missionários. Diante de tal reação, o governador desistiu do ald eamento, mas manteve a proposta de permanência dos índios na vila. Dom Xiclano, contudo, não aceitou as novas condições e, por conseguinte, interrompeu as negociações. ${ }^{21}$ Alguns índios,

19 Autor anônimo. "Catequese e aldeamento dos minuanos" [1750/51]. In: Cesar, Guilhermino. Primeiros cronistas do Rio Grande do Sul: estudo de fontes primárias da história rio-grandense acompanhado de vários textos. Porto Alegre: Ed. da UFRGS, 1998. p.122.

20 Almeida, Maria Regina Celestino de. Metamorfoses indígenas: identidade e cultura nas aldeias coloniais do Rio de J aneiro. pp.62 e segs.

21 Autor anônimo. "Catequese e aldeamento dos minuanos" [1750/51]. In: Cesar, Guilhermino, Primeiros cronistas do Rio Grande do Sul: estudo de fontes primárias da história rio-grandense acompanhado de vários textos. pp.122-123. 
porém, permaneceram em Rio Grande, onde foram batizados e apadrinhados pelo próprio governador e por outras pessoas de destaque na freguesia. Não receberam, contudo, um aldeamento. Os homens foram enviados à estância real do Bojuru, onde se dedicavam, mediante o pagamento, pelo menos em tese, de salário, às atividades do manejo de gado. As mulheres, por sua vez, foram alocadas nas casas de suas madrinhas, onde deveriam receber a educação considerada condizente com o sexo feminino. ${ }^{22}$

A partir desta negociação para o aldeamento de alguns grupos de minuanos pode-se perceber como eles, em uma situação de necessidade, negociaram com os portugueses e como esta negociação se deu através de avanços e recuos, pois é uma clara situação onde se fizeram presentes os interesses conflitantes de vários segmentos da sociedade. O governador, seguindo as diretrizes da Coroa, ansiava o aldeamento dos índios, mas encontrou restrições por parte dos moradores da vila. Devido a tais restrições, teve de mudar a sua oferta aos índios propondo, em detrimento de um aldeamento, onde eles ficariam reunidos e, provavelmente, teriam algum tipo de autonomia ${ }^{23}$, uma outra solução, a qual separaria os grupos e os deixaria sujeitos aos desígnios dos moradores e das autoridades coloniais, uma vez que estariam diretamente vinculados a estes. Esta nova proposta não agradou a todos, pois dom Xiclano desistiu das negociações. Pareceu, porém, razoável para outros e, por conseguinte, cerca de sessenta aceitaram o batismo, marco característico da entrada dos índios na sociedade colonial ${ }^{24}$.

Paralelamente às negociações de aldeamento, os portugueses continuavam mantendo relações com outros grupos de minuanos. Estes, por sua vez, se aceitavam as ofertas dos lusitanos e, em muitos casos, os auxiliavam, não percebiam estas alianças como exclusivas. Muitos minuanos mantinham as suas solidariedades pregressas com grupos não alinhados aos lusitanos, às quais eram justapostos os acordos com os portugueses. Foi o que ocorreu em 1749, quando alguns minuanos se dirigiram a uma estância do povo jesuítico de São Miguel para avisar os seus parentes cristãos aldeados sobre as pretensões dos portugueses de atacarem as missões. Estes minuanos estavam em contato com os lusitanos no forte de São Miguel, onde ficaram sabendo de tais intentos e, provavelmente,

22 Autor anônimo. "Catequese e aldeamento dos minuanos" [1750/51]. In: Cesar, Guilhermino, Primeiros cronistas do Rio Grande do Sul: estudo de fontes primárias da história rio-grandense acompanhado de vários textos. p.122.

23 Os aldeamentos eram definidos pela historiografia como um local de mera imposição aos índios da dominação colonial, onde eles não detinham nenhum grau de autonomia e/ou de ingerência. Trabalhos recentes, porém, têm avançado na perspectiva de que aqueles espaços foram construídos também pelos próprios índios, que lhes atribuíram os seus próprios significados e passaram a percebê-los como um importante espaço de sobrevivência no interior da sociedade colonial. Almeida, Maria Regina Celestino de. Metamorfoses indígenas: identidade e cultura nas aldeias coloniais do Rio de J aneiro. p.119.

24 Sobre o lugar simbólico que o batismo ocupava na relação entre os índios e a sociedade colonial veja-se: Vainfas, Ronaldo. A heresia dos índios: catolicismo e rebeldia no Brasil colonial. São Paulo: Companhia das Índias, 1995. pp.121 e segs. 
tinham acertado com os mesmos a sua participação na ação. No entanto, devido à presença de seus parentes em algumas reduções, foram avisá-los da iminência do perigo. ${ }^{25}$

\section{A preferência dos minuanos pelos portugueses}

Os minuanos, conforme visto, não percebiam a sua aliança com os portugueses como exclusiva e, tampouco, esta era um impedimento para eventuais acordos com os espanhóis e com os missioneiros. No entanto, a sua preferência em aliar-se com os portugueses foi percebida por vários agentes coloniais, a serviço de ambos os Impérios ibéricos, como uma tendência ao longo do século XVIII. Como pode ser explicada esta tendência? Segundo o administrador espanhol Gonzalo de Doblas, os minuanos preferiam os lusos aos castelhanos porque aqueles Ihes outorgavam mais dádivas:

Pero es mucho más lo que extraen los mismos portugueses, a los que ayudan y favorecen mucho los Minuanes, porque los regalan con más frecuencia, dándoles lo que más apetecen, particularmente el aguardiente, pormedio de lo cual consiguen, no tan solamente el que les permitan matar y extraer to do el ganado que quieren y sus corambres, sino que, en caso de que alguna partida española los encuentre, los favorecen, no permitiendo se les haga ningún mal. ${ }^{26}$

Assim, de acordo com Doblas, os minuanos não apenas comerciavam com os portugueses, mas também os defendiam dos perigos existentes na campanha. Para o engenheiro luso J osé de Saldanha, que esteve na região em meados de 1780, a preferência dos minuanos pelos portugueses era um fato consumado. A sua explicação para esta questão vai na mesma direção da de Doblas, enfatizando que a maior "amizade" se devia ao maior número de "dádivas" outorgadas por aqueles aos índios. ${ }^{27}$ Considerando a convergência dos relatos, parece que os portugueses demonstravam uma maior capacidade de atrair esta população, principalmente através da concessão de "mimos", empregados tanto como uma forma de aliciá-los quanto de afastá-los dos espanhóis.

A mera constatação, contudo, de que as alianças entre os portugueses e os minuanos era baseada na outorga de mimos não é suficiente para explicá-la. Primeiramente, porque nesta relação os mimos deveriam

250 padre Nusdorfer, Superior das Missões do Uruguai, denuncia os intentos dos portugueses de povoar as cabeceiras e margens do Rio Negro, afluente do [rio] Uruguai. 29 de maio de 1749. In: Cortesão, J aime (organização e anotação). Alexandre de Gusmão e o Tratado de Madri. parte III: Antecedentes do Tratado, tomo II. Rio de J aneiro: Ministério das Relações Exteriores, Instituto Rio Branco, 1951. pp.502-503.

26 Doblas, Gonzalo de. Memoria histórica, geográfica, política y económica sobre la provincia de Misiones de indios guaranís. Alicante: Biblioteca Virtual Miguel de Cervantes, 2002 [1785]. p.55.

27 Saldanha, J osé de. "Diário resumido e histórico" [1787]. In: Anais da Biblioteca Nacional. Rio de J aneiro: Biblioteca Nacional, 1938. vol.LI, p.236. 
ser constantes, sendo os acordos selados caso a caso, uma vez que não existiam como algo estabelecido e passível de ser acionado automaticamente. A supressão das dádivas poderia facilmente tornar inexeqüível a efetivação dos acordos e levar os índios a buscar outros parceiros, fossem eles portugueses ou espanhóis.

Por outro lado, considerar estes mimos como uma simples relação de troca pode empobrecer a análise, na medida em que, segundo alguns indícios, eles estavam baseados em uma perspectiva ritual, onde as trocas deveriam ser veladas. Conforme J osé de Saldanha, aos minuanos não thes aprazia o comércio em si, algo que só faziam quando se encontravam em necessidade de determinadas mercadorias. Pelo contrário, Ihes agradava receber de presente os produtos de que necessitassem. Segundo o autor:

Estimam, gostam e diligenciam para que se lhe dê tudo o que precisam, de regalo, porém postos em necessidade fazem as suas viagens, a algumas das Povoações meridionais de Missões, e Fronteira de Rio Pardo, conduzindo alguns cavalos dos seus apanhados no campo, pares de bolas, e cayapis novos para trocarem por era-mate, panos de algodão, faças flamengas, tabaco de fumo, aguardente ou alguns freios. ${ }^{28}$

A se dar crédito à narrativa de Saldanha, os minuanos gostavam de ser presenteados. Considero, portanto, que os portugueses não eram geralmente preferidos pelos minuanos porque eles oferecessem mais dádivas do que os espanhóis, mas talvez porque soubessem melhor como oferecer estas dádivas. Esta preferência, por sua vez, era defendida pelos próprios minuanos, os quais dela se valiam em seus contatos com os lusitanos para se valorizar perante eles. Assim, se firmavam alianças com os espanhóis e/ou com os índios missioneiros, não comentavam sobre elas em seus contatos com os portugueses. Pelo contrário, durante as suas conversações, se apresentavam enquanto um grupo caracterizado pela sua vinculação aos lusitanos, diferenciando-se dos demais indígenas da região, embora não deixassem de manter contato com eles, inclusive com os missioneiros. Em certos episódios ocorridos durante as tentativas de demarcação do Tratado de Madri, por exemplo, os minuanos firmaram acordos com os portugueses e fizeram um jogo duplo, pois também se apresentaram como aliados aos missioneiros. Foi o caso do cacique Moreira que, "fingindo-se" de aliado dos missioneiros, solicitou aos mesmos alguns presentes, principalmente carne, tabaco e erva, com os quais pretendia dirigir-se ao acampamento dos portugueses e "enganá-los". Ao retornar, Moreira teria dito aos índios para se afastarem do seu acampamento, pois os lusos viriam revidar os falsos presentes outorgados. Segundo parece, os índios desconfiaram

28 Saldanha, J osé de. "Diário resumido e histórico" [1787]. p.236. Grifos meus. 
que Moreira estava mancomunado com os portugueses, mas decidiram acatar o seu pedido. ${ }^{29}$ As desconfianças não eram sem fundamento, pois Moreira, quando os índios foram fazer frente ao exército português, entrou em conversação com o general Gomes Freire de Andrada.

Durante as negociações, Gomes Freire disse a Moreira que se sentia desconfortável com a união dos minuanos com os guaranis, afinal ele sempre tinha sido amigo da sua "nação". Moreira, no entanto, contou uma versão favorável a si sobre o acordo com os missioneiros. Segundo a sua justificativa, ele não tinha feito o acordo porque queria, mas porque o seu grupo se encontrava em um estado de penúria. Conforme a sua versão, os minuanos estavam em extrema necessidade de "coisas" e perceberam nos guaranis uma possibilidade de abastecer-se. Após esclarecer a situação com Gomes Freire, Moreira teria dito: "que ele estava violento na companhia daquela gente [missioneiros]: se eu [Gomes Freire] Ihe dava palavra de achar em mim o antigo amparo, ele moveria os seus a negar o socorro e se recolheriam a fortaleza de São Miguel". ${ }^{30}$

O importante a frisar neste caso é como Moreira representou a si e a seu grupo no diálogo com Gomes Freire. As ações do seu grupo que teriam "desapontado" o general são imputadas a determinadas situações ou a terceiros. Dessa forma, os minuanos não se aliaram aos missioneiros porque quiseram, mas pela necessidade na qual se encontravam. $E$, ainda mais importante, foi devido a esta aliança, a qual se viram obrigados pelas circunstâncias, que estavam "violentos". Nesse sentido, as ações contrárias aos portugueses não deveriam ser creditadas aos minuanos, mas sim às suas "más companhias": os missioneiros. Nas palavras de Moreira, uma vez restabelecida a habitual troca de dádivas entre portugueses e minuanos, aqueles encontrariam neles o "antigo amparo", pois os minuanos não tinham mudado de lado nem traído os lusitanos, apenas, de acordo com o diálogo, passado por uma situação adversa.

Esta condição de escolha dos portugueses pelos minuanos era constantemente retomada durante os contatos entre ambos. Foi assim, por exemplo, em maio de 1785, quando o cacique Bartolomeu enviou uma carta ao governador interino do Continente de São Pedro, Rafael Pinto Bandeira, na qual solicitava licença para passar aos domínios de Portugal. Nas suas palavras:

Sr. Coronel Rafael Pinto Bandeira. Deus nosso senhor seja na sua companhia. Nós todos mandamos muitas lembranças a VS, suposto que não somos ba-

29 Henis, Pe. Tadeo Xavier. “Diário histórico de la rebelión y guerra de los pueblos guaranís, situados en la costa oriental del río Uruguay, del año de 1754". Alicante: Biblioteca Virtual Miguel de Cervantes, 2002. pp.33-34 e 40.

30 Ofício de Gomes Freire de Andrade para Sebastião J osé de Carvalho e Melo, em que se refere aos índios minuanos. Rio Grande, 20 de fevereiro de 1755. In: Anais da Biblioteca Nacional. Rio de J aneiro: Biblioteca Nacional, 1928. vol.L, p.456. 
tizados Cacique Bartolomeu. Dou parte a VS em como os castelhanos vieram falar conosco no Campo; e peço a VS que não prenda aos portugueses que andam nestes campos, que eles não nos fazem mal: os castelhanos querem que nós cheguemos a Montevidéu, que nos darão tudo quanto nós quisermos e nós não queremos e antes queremos entregar-nos ao Rei de Portugal e também queremos passar o gado de São Nicolau e São Izidro para lá com toda a minha família e quero que VS saiba disto e que nos conceda licença e espero de VS a resposta. ${ }^{31}$

Pode-se perceber nesta missiva como o cacique maneja muito bem as rivalidades entre os ibéricos a seu favor. Enfatiza que foi convidado a passar para Montevidéu, mas não quer, ou melhor, prefere os domínios portugueses, expondo ainda que levará recursos para tal, deixando claro que a sua entrada nas terras do Rei Fidelíssimo seria um bom negócio para os lusos. As relações do grupo de dom Bartolomeu com os espanhóis, porém, não eram tão harmônicas quanto ele descreveu na carta. No breve período entre o envio da mesma e a deliberação das autoridades portuguesas sobre 0 assunto, o seu grupo foi "destroçado" pelos castelhanos, ele ficou "sem gente" e se viu obrigado a reunir-se a outros caciques. ${ }^{32} 0$ grupo de caciques ao qual se reuniu dom Bartolomeu deu prosseguimento às negociações relativas à passagem dos minuanos aos domínios do Rei Fidelíssimo. Para tal fim, a administração lusitana solicitou aos mesmos que respondessem algumas questões sobre as suas intenções. Estas eram:

- Que número de gente governa;

- Quantos homens, e quantas mulheres;

- Quais são os motivos que os obrigam a passar para os domínios de Portugal;

- Que número de animais pretendem trazer, declarando quanto de gado, quantos cavalos, etc;

- Quais são as condições com que querem ser admitidos;

- Se precisam de auxílio para passarem, ou se poderão fazer sem ele;

- Que se deve conservar um impenetrável segredo, a fim de que os espanhóis não presumam de tal negócio;

- Em que tempo estão prontos a passar ${ }^{33}$

O grupo era composto por cinco caciques, entre os quais dom Bartolomeu. Ao todo, eram cerca de mil pessoas, distribuídas em: "Minuanos de armas, digo de lanças 300 e tantos, mulheres 270 e tantas, menores 420 e

31 Carta do cacique minuano Bartolomeu a Rafael Pinto Bandeira, solicitando licença para passar aos domínios portugueses. Missões, 7 de maio de 1785. Biblioteca Nacional/Rio de J aneiro, 9,4,14 p.511 no. 232 (em guarani) no. 233 (traduzida para o português).

32 Carta de Rafael Pinto Bandeira para o Vice-Rei. Rio Grande, 16 de abril de 1786. Arquivo Nacional/Rio de J aneiro - Fundo: Secretaria de Estado do Brasil, cód.104, vol.08, fl.101.

33 Relação dos cinco caciques com quem falei e da gente que tem e as causas porque querem vir para os domínios de Portugal, e dos animais com que se acham aos 13 de abril de 1786. J osé Carvalho da Silva, Tenente. Arquivo Nacional/Rio de J aneiro - Fundo: Secretaria de Estado do Brasil, cód.104, vol.08, fls.206-207. 
tantos" e possuíam um rebanho de aproximadamente quatro mil cabeças. Em resposta às questões colocadas, os caciques alegaram que queriam ser vassalos de D. Maria I porque os portugueses tinham sido sempre seus amigos. Além disso, os espanhóis estavam querendo expulsá-los dos "campos, em que habitam, e seus antecessores de muitos séculos, que por direito são seus, por serem os primeiros povoadores deles". Acrescentaram, ainda, que o Rei de Castela queria matá-los. Devido a tais arbitrariedades dos espanhóis, os caciques se ofereciam para serem os primeiros a combatê-los em qualquer eventual guerra. ${ }^{34}$

Além de se queixarem aos portugueses dos espanhóis, algo que se to rnou um hábito entre os minuanos, o mais relevante nesta solicitação do grupo liderado pelo cacique Bartolomeu é a justificativa por eles empregada. Apresentaram-se, primeiramente, como aliados antigos dos portugueses, ou seja, suas relações estavam baseadas na história. Por outro lado, manejaram com habilidade as rivalidades luso-castelhanas, pois seriam os primeiros a combater os espanhóis e, mais do que isto, colocaram-se ao lado dos lusitanos por terem um inimigo em comum, acrescentando que 0 Rei de Castela queria matá-los, deixando clara uma diferença, na sua percepção, dos monarcas ibéricos em relação a eles. É importante ressaltar ainda a posição em que os minuanos se colocaram na missiva. Eles se encontravam em uma situação difícil, com as suas terras ameaçadas e, a ser dar crédito à sua narrativa, as suas vidas estavam em perigo. Mais do que simplesmente evidenciar o momento periclitante que estavam atravessando, o caso demonstra que o aprendizado dos minuanos das rivalidades lusocastelhanas e dos possíveis benefícios que poderiam ser delas auferidos foi concomitante ao processo de expansão da colonização ibérica. Assim, souberam acionar os instrumentos, o vocabulário e a retórica adequados para, naquela situação, utilizar a sua posição na fronteira dos Impérios ibéricos para reafirmarem o seu valor enquanto aliados dos lusitanos.

Outras pesquisas sobre grupos subalternos em regiões de fronteira têm apontado situações semelhantes. J ane Landers, por exemplo, em estudo sobre os escravos africanos que fugiam dos domínios ingleses na América do Norte para o nordeste da Flórida espanhola em busca de obter a sua liberdade, demonstra como aqueles aprenderam a utilizar em seu favor as rivalidades anglo-espanholas. Neste processo, eles não apenas se construíram como aliados dos últimos, aproveitando-se dos benefícios oferecidos pela administração espanhola, interessada nestes aliados, mas também aprimoraram a sua capacidade de manejar o aparato legal espanhol. ${ }^{35}$

34 Relação dos cinco caciques com quem falei e da gente que tem e as causas porque querem vir para os domínios de Portugal, e dos animais com que se acham aos 13 de abril de 1786. J osé Carvalho da Silva, Tenente. Arquivo Nacional/Rio de J aneiro - Fundo: Secretaria de Estado do Brasil, cód.104, vol.08, fls.206-207.

35 Landers, J ane. "Gracia Real de Santa Teresa de Mose: A Free Black Town in Spanish Colonial Florida". The American Historical Review. Washington: American Historical Association, February 1990, vol.95, n.1. p.21. 
Ao manejarem as rivalidades luso-castelhanas, os minuanos não se colocavam em uma posição subalterna em relação aos portugueses. Ao contrário, se apresentavam aos mesmos enquanto aliados convenientes, com os quais compartilhavam um inimigo. No momento desta negociação, início do último quartel do século XVIII, o território habitado pelos minuanos estava sendo cada vez mais ocupado pelas frentes colonizadoras ibéricas e, conseqüentemente, seu espaço sendo reduzido. Na versão apresentada pelos referidos caciques aos portugueses, porém, a situação era outra: não estavam pressionados pelas duas frentes de expansão, mas apenas pelos espanhóis. Neste momento de inflexão, os minuanos, em uma situação de interação com os lusitanos, recontaram a sua história e, a partir desta, reorganizaram o seu presente, mostrando uma versão específica de um processo mais geral. J oanne Rappaport, ao estudar a consciência história dos páez da Colômbia, demonstra como, para aquele grupo, a história era constantemente reformulada a partir de questões colocadas pelo presente, quando os índios utilizavam o passado para repensar as suas condições atuais e planejar o futuro. ${ }^{36}$ Para o caso dos minuanos, os argumentos empregados e o contexto histórico demonstram que eles percebiam na sua trajetória de aliança com os portugueses a possibilidade de terem um futuro, na medida em que buscavam alternativas para escapar da situação de pressão na qual se encontravam.

As queixas dos minuanos para os portugueses acerca dos espanhóis parecem ter se tornado uma prática, pelo menos nas últimas décadas do século XVIII. Assim, o processo constante de recriação do seu passado e as recorrentes tentativas de representar a si mesmos enquanto aliados dos portugueses e inimigos dos espanhóis eram também uma maneira de apropriar-se da sua história passada e de compreender a sua situação naquele momento. Longe de acusarem os portugueses de serem também responsáveis pela sua situação, se posicionaram enquanto seus aliados, junto dos quais construíram a conjuntura na qual se encontravam e, a partir deste processo, se posicionavam historicamente enquanto responsáveis pela sua própria trajetória, retomando, por conseguinte, a capacidade de tomar decisões sobre as suas vidas. ${ }^{37}$

Esta argumentação, no entanto, não foi suficiente para obter do vice-rei, Luiz de Vasconcelos e Souza, um parecer favorável. Na sua apreciação, esta aliança poderia suscitar desequilíbrios na relação com os espanhóis, justamente em um momento onde as duas Cortes tentavam demarcar as divisas previstas no Tratado de Santo Ildefonso. Para Luiz de Vasconcelos

36 Rappaport, J oanne. "Introduction: Interpreting the Past". In: University Press, 1990. pp.1-25.

37 Sobre a relação entre a retomada dos índios da sua própria história e as situações políticas específicas por eles vivenciadas veja-se: Hill, J onathan. "Contested Pasts and the Practice of Anthropology: Overview". American Anthropologist. Washington: American Anthropological Association, 1992. vol.94, n.4. 
e Souza, o número de vassalos e o de animais não era suficiente para justificar o risco de uma possível inimizade espanhola, além de também não acreditar na fidelidade dos índios, empregando como argumento a sua "natural inconstância". ${ }^{38}$ Tal "inconstância", percebida por alguns portugueses como uma característica intrínseca dos minuanos, nada mais era, a meu ver, do que os reflexos de suas diferentes escolhas em momentos específicos. Por outro lado, esta percepção deveria ser recíproca, pois os próprios minuanos também deveriam caracterizar os lusitanos como inconstantes, já que ora valorizavam as suas alianças, ora não os consideravam aliados pertinentes.

Em abril de 1787, o governador do Rio Grande, Sebastião Xavier da Veiga Cabral da Câmara, estava na região da campanha devido aos trabalhos das comissões demarcadoras do Tratado de Santo Ildefonso. Em certa ocasião, encontrou um grupo de minuanos e fez uma breve descrição dos mesmos. 0 grupo era chefiado por dom Miguel, um dos caciques envolvidos nas negociações acima citadas, e, segundo as informações de Cabral da Câmara, encontrava-se em sérias dificuldades. Teriam se apresentado: "descalços, e quase nus alguns índios gentios da diminuta e pobríssima Nação Minuana". ${ }^{39}$ Por este relato, os minuanos com os quais travou contato estavam passando por um momento difícil. A menção a estarem descalços e quase nus pode ser considerada como um indicativo desta situação. Longe de ser uma constatação eurocêntrica sobre os índios, descreve, provavelmente, uma condição indesejada pelos minuanos, pois as referências a estes ao longo do século XVIII dão conta de que lhes apraziam as roupas e os símbolos europeus, os quais foram muitas vezes moeda de toca entre eles e os portugueses. Para atenuar esta situação de necessidade, o recurso a tentativas de aproximação e vinculação aos lusos poderia se apresentar novamente como uma das possibilidades mais promissoras. Foi, provavelmente, com esta intenção que se apresentaram a Cabral da Câmara. Nestas negociações, as suas lideranças desempenhavam um papel de destaque, sendo as responsáveis pelos contatos e ajustes com os lusitanos.

38 Ofício do [vice-rei do Estado do Brasil], Luís de Vasconcelos e Sousa, ao [secretário de estado da Marinha e Ultramar], Martinho de Melo e Castro, informando as propostas impraticáveis apresentadas pelo coronel Rafael Pinto Bandeira, como a passagem de famílias de índios Minuanos dos domínios espanhóis para o lado português, a fim de se fixarem nos terrenos de Vacaí com gados e outros animais; referindo as dificuldades a encontrar na execução de tal plano, e os conflitos que poderiam surgir nas relações luso-castelhanas. Rio de J aneiro, 30 de dezembro de 1786. Arquivo Histórico Ultramarino, Rio de J aneiro, cx. 128, d. 10244.

39 Carta do governador Sebastião Xavier da Veiga Cabral da Câmara para o vice-rei, Luiz de Vasconcelos e Sousa. Acampamento de Monte Grande, 14 de abril de 1787. Arquivo Nacional/Rio de J aneiro - Fundo: Secretaria de Estado do Brasil, cód.104, vol.09, fl.87. 


\section{As lideranças dos minuanos}

Às lideranças dos minuanos cabiam a escolha dos mecanismos de aproximação, dos meios a serem utilizados e, principalmente, o ajuste dos termos das negociações. Quem eram estas lideranças? Como se construíam e em que bases agiam?

Segundo Gonzalo de Doblas, o exercício da liderança entre os minuanos estava calcado em dois quesitos principais: a quantidade de índios que 0 cacique em potencial tinha sob seu comando e o valor nele reconhecido pelos demais. Conforme o autor: "regularmente conocen [os minuanos] superioridad en alguno de los caciques de aquellos territorios, ya por tener mayor número de indios a su devoción, o por más valeroso y hábil". ${ }^{40}$

Dada a trajetória dos minuanos de contatos com os europeus e, especialmente, com os portugueses, um dos aspectos que passou a ser cada vez mais valorizado nas lideranças era a capacidade de realizar negociações com os membros da sociedade colonial. Apesar da maior parte dos minuanos não viver diretamente nos domínios ibéricos, muitos o faziam, não de forma permanente, mas passando um tempo junto aos portugueses ou espanhóis e, depois, regressando aos seus toldos. ${ }^{41}$ Foi este 0 caso do cacique dom Miguel, com quem travou contato J osé de Saldanha. Conforme as suas anotações, dom Miguel permaneceu mais de vinte anos trabalhando como peão em uma estância portuguesa e, posteriormente, retornou para junto dos minuanos. ${ }^{42}$ Segundo as informações disponíveis, dom Miguel era um mestiço biológico, filho de uma índia minuana e de um paraguaio com origem espanhola. Teria passado a infância entre os minuanos e, não se sabe ao certo com que idade, ido trabalhar na referida estância. ${ }^{43}$

0 aspecto de dom Miguel ter trabalhado por mais de vinte anos em uma estância portuguesa e, posteriormente, retornado para junto de um grupo de minuanos demonstra que, apesar de muitos grupos indígenas não viverem diretamente sob o domínio da sociedade colonial, as suas trajetórias estavam imbricadas com esta. Nesse sentido, deve-se ressaltar que as idéias dicotômicas segundo as quais os índios ou manteriam a sua vida "tradicional" ou a abandonariam e iriam viver junto dos portugueses são demasiado esquemáticas e não traduzem a complexidade das suas vivências. Durante o seu trabalho na estância, dom Miguel conviveu dentro da sociedade colonial, construiu alianças e acumulou aprendizados. A questão é que alguns autores concluem que durante a convivência dos minuanos com a sociedade colonial se inicia um processo inexorável a

40 Doblas, Gonzalo de. Memoria histórica, geográfica, política y económica sobre la provincia de Misiones de indios guaranís. p.55.

41 Termo empregado na época para designar a habitação dos minuanos.

42 Saldanha, J osé de. "Diário resumido e histórico" [1787].

43 Porto, Aurélio. História das Missões Orientais do Uruguai. Porto Alegre: Livraria Selbach, 1954. p.43. 
partir do qual eles começam a ser despojados da sua "cultura tradicional", sendo que resíduos desta se tornam aspectos folclóricos da população supostamente originada da mestiçagem entre os índios, os portugueses e os espanhóis: os gaúchos. ${ }^{44}$

Por outro lado, é importante problematizar o que significava para os índios, neste período histórico, trabalhar como peão em uma estância portuguesa. Para Caio Prado J únior, esta foi uma marca da presença dos índios no atual estado do Rio Grande do Sul, cuja conseqüência era a integração dos mesmos em um estatuto inferior na sociedade colonia $4{ }^{45}$. A ocupação dos índios como peões foi também destacada por boa parte da historiografia sobre a região, geralmente sem maiores considerações sobre o tema ou então com abordagens próximas a de Prado J únior, ou seja, percebendo esta atividade como algo a meio caminho na passagem, considerada inevitável e linear, de índio para mestiço. Nestes trabalhos, esta passagem é considerada, implícita ou explicitamente, como um afastamento dos índios das suas comunidades e dos seus vínculos, considerando-os "indivíduos despojados de sua cultura tradicional", os quais ficariam cada vez mais dependentes do poder discricionário dos grandes proprietários de terras para os quais trabalhavam.

O caso de dom Miguel, porém, aponta para outra direção, qual seja, a de que trabalhar em uma estância poderia trazer também benefícios para os índios, principalmente para aqueles que mantinham laços com o seu grupo de origem. Parece-me, portanto, pelo menos para o período tratado, que trabalhar em uma estância como peão não significava "deixar de ser índio", mas apenas mais uma possibilidade para as populações nativas. Durante as suas atividades, os índios poderiam obter determinados benefícios materiais, construir relações dentro da sociedade colonial e aprender como esta funcionava. Assim, se dom Miguel mudou durante a sua estadia junto dos portugueses, os seus aprendizados foram aproveitados pelo seu grupo. Ele não necessariamente "perdeu" cultura, mas, pelo contrário, ganhou habilidades. Segundo Regina Celestino, a partir do estudo das dinâmicas das populações indígenas e das suas relações com a sociedade colonial, as mudanças das mesmas devem ser pensadas para além de "perdas culturais, mas também como propulsoras de novas possibilidades dos índios adaptarem-se à Colônia". ${ }^{46} \mathrm{O}$ capital social adquirido durante 0 trabalho em uma estância poderia ser usado em benefício próprio pelo índio, por meio do qual ele alcançaria vantagens pessoais, entre as quais realçar a sua capacidade para um possível exercício da liderança, uma vez que ele seria um

\footnotetext{
44 Porto, Aurélio. "O minuano na toponímia rio-grandense".

45 Prado J únior, Caio. História econômica do Brasil. São Paulo: Brasiliense, 1973 [1945]. 16a. ed. p.98.

46 Almeida, Maria Regina Celestino de. Metamorfoses indígenas: identidade e cultura nas aldeias coloniais do Rio de J aneiro. p.129.
} 
dos índios mais indicados para desempenhar tal papel, pois saberia como lidar com a sociedade colonial. Assim, a vida junto da sociedade colonial não acarretava apenas perdas para os índios, no sentido de destruição do seu modus vivendi "tradicional", mas também proporcionava experiências aos índios, manejadas, quando julgado pertinente, a seu favor. ${ }^{47}$

J oanne Rappaport, ao analisar as lideranças contemporâneas dos páez na Colômbia, demonstrou que muitos dos seus líderes mais importantes não foram criados na comunidade e, os poucos que o foram, passaram distante desta pelo menos uma boa parte das suas vidas. Segundo a autora, este período lhes forneceu instrumentos para lidar com os trâmites, principalmente burocráticos, da sociedade envolvente. E foi justamente este conhecimento que lhes conferiu, ao retornarem às suas respectivas comunidades, uma visão de poder, materializado na sua habilidade, superior aos demais, em manejar a burocracia estatal, adquirida durante a sua vivência no contexto da sociedade nacional. ${ }^{48}$

Neste sentido, é elucidativo que J osé de Saldanha, ao descrever os cinco caciques minuanos com os quais travou contato, tenha classificado dom Miguel como o "mais racionável", ${ }^{49}$ ou seja, dentre as lideranças, ele era quem mais se aproximava da visão de mundo do engenheiro, o cacique com quem ele conseguia se entender melhor. Por conseguinte, se ele era considerado o mais racionável, era, provavelmente, a pessoa mais indicada para exporaos portugueses as demandas dos minuanos e para encabeçar negociações com maiores possibilidades de obter benefícios.

\section{Conclusões}

Conforme visto ao longo do texto, os índios minuanos tiveram uma trajetória de aliança com os portugueses. Tal aliança, porém, não foi absoluta e, tampouco, ininterrupta. Melhor do que falar em aliança dos minuanos com os portugueses, seria utilizar o termo no plural, pois se trataram negociações feitas ao longo do tempo, por grupos diferentes e em momentos específicos. Os acordos e as relações dos minuanos com a sociedade colonial se modificaram consideravelmente com o desenrolar da ocupação lusitana na região. Considerados, no princípio do século XVIII, indispensáveis para a manutenção da Colônia de Sacramento, os minuanos foram caracterizados, no início do século XIX, como "úteis como amigos, mas pouco

47 Segundo J oão Pacheco de Oliveira, em texto sobre a "emergência" de identidades étnicas no nordeste contemporâneo: "a 'etnologia das perdas' deixou de possuir um apelo descritivo ou interpretativo e a potencialidade da área do ponto de vista teórico passou a ser o debate sobre a problemática das emergências étnicas e da reconstrução cultural”. O liveira, J oão Pacheco de. "Uma etnologia dos 'índios misturados': situação colonial, territorialização e fluxos culturais". In:_____org.) A viagem de volta: etnicidade, política e reelaboração cultural no Nordeste indígena. Rio de J aneiro: Contra Capa Livraria, p.19.

48 Rappaport, J oanne. "Introduction: Interpreting the Past". pp.21-22.

49 Saldanha, J osé de. “Diário resumido e histórico" [1787]. p.235. 
temíveis como inimigos". ${ }^{50} \mathrm{~A}$ região por eles habitada converteu-se em um espaço cada vez mais disputado pelas Coroas ibéricas e eles passaram a depender da sociedade colonial para abastecer-se de mercadorias e, principalmente, foram compelidos a desenvolver novas práticas políticas e sociais para conseguirem manter-se naquele território. É evidente, portanto, que os acordos eram desiguais e que os minuanos estavam em crescente "ameaça" pelas frentes expansionistas ibéricas. Por outro lado, nem sempre a estratégia de se passar por amigos dos portugueses surtiu os resultados esperados, conforme já visto. Isto, porém, não impediu que a mesma continuasse sendo empregada pelos minuanos.

J ane Landers, no seu já citado estudo sobre os escravos que fugiam dos domínios ingleses em direção à Flórida, expõe que as diretrizes do governo espanhol em relação aos fugitivos variavam de acordo com diferentes conjunturas, desde o estado das relações diplomáticas entre a Inglaterra e a Espanha até os diferentes pontos de vista dos governadores espanhóis sobre a questão. No entanto, segundo a autora, para os escravos fugitivos 0 estabelecimento de alianças com o governo da Flórida era fundamental para a sua sobrevivência, razão pela qual não desistiam quando encontravam uma conjuntura adversa e, paralelamente, sabiam ap roveitar os momentos mais favoráveis a suas demandas. ${ }^{51}$

Considero tal situação similar a dos minuanos. Eles buscaram, ao longo do século XVIII, construir uma imagem de si enquanto aliados dos portugueses e esta estratégia nem sempre trouxe os resultados esperados. Algumas vezes foram bem recebidos e tratados com uma série de distinções. Em outras ocasiões, foram rechaçados e preteridos em prol da manutenção de relações amistosas com a Espanha. Pelas fontes consultadas, porém, parece que, apesar das adversidades, o estabelecimento de alianças com os portugueses era concebido como uma das melhores possibilidades disponíveis e a ela recorriam quando julgavam pertinente.

Assim, se os minuanos foram caracterizados historicamente como aliados dos portugueses, esta caracterização não significa que eles não tivessem maiores contatos e alianças com os espanhóis e/ou com os missioneiros. 0 importante a perceber sobre esta questão é que os minuanos assim se apresentavam diante dos portugueses, ou seja, foi uma estratégia elaborada e aperfeiçoada ao longo do tempo pelos próprios em busca de maiores benefícios em seus contatos com a sociedade colonial. Estes benefícios, por sua vez, não eram absolutos, mas relativos às situações específicas que enfrentavam. Poderiam ser, entre outros, o acesso a

50 Ofício de Paulo J osé da Silva Gama a Patrício J osé Corrêa da Câmara, Comandante da Fronteira do Rio Pardo, mostrando-lhe como os índios como amigos, eram úteis e como inimigos, pouco temíveis para serem aniquilados. Porto Alegre, 13 de dezembro de 1805. Instituto Histórico e Geográfico Brasileiro - Arq. 1.2.19 p.268v.

51 Landers, Jane. "Gracia Real de Santa Teresa de Mose: A Free Black Town in Spanish Colonial Florida". 
roupas, em uma região caracterizada por um inverno rigoroso, e a certas manufaturas européias, como lanças de ferro. 0 principal ganho obtido com esta estratégia, porém, era dispor de abrigo junto aos portugueses quando se sentissem ameaçados. Se tais vantagens podem ser consideradas modestas a partir da perspectiva ocidental, certamente não o foram pelos minuanos, que empreenderam grandes esforços para obtê-las. 